\title{
XAF1 expression levels in a non-small cell lung cancer cohort and its potential association with carcinogenesis
}

\author{
LUCIENE SCHLUCKEBIER $^{1}$, VERONICA ARAN ${ }^{1}$, JOYCE DE MORAES ${ }^{1}$, HEITOR PAIVA $^{2}$, \\ CINTHYA STERNBERG ${ }^{1,3}$ and CARLOS GIL FERREIRA ${ }^{1,3,4}$ \\ ${ }^{1}$ Clinical Research Division and ${ }^{2}$ Pathology Division, Brazilian National Cancer Institute (INCA); \\ ${ }^{3}$ Cancer Foundation, Rio de Janeiro, Brazil
}

Received November 1, 2016; Accepted January 26, 2017

DOI: $10.3892 /$ or.2017.5680

\begin{abstract}
The process of lung carcinogenesis is still not well understood and involves different levels of regulation of several genes. The search for molecular biomarkers, which can be applicable to clinical practice, has been the focus of various studies. XIAP-associated factor 1 (XAF1) was previously shown to be downregulated in many types of tumors, including squamous cell lung cancer. XAF1 is a pro-apoptotic protein and its restoration was found to sensitize cancer cells to apoptotic stimuli; however, the precise mechanism involved in the downregulation of XAF1 in tumors is unknown and promoter hypermethylation or heat-shock transcription factor 1 (HSF1) may be involved. Therefore, the aim of the present study was to evaluate the expression of XAF1 in tumors and adjacent non-tumor specimens from non-small cell lung cancer (NSCLC) patients, and its potential association with various factors including clinicopathological characteristics and other genes involved in NSCLC. Our results indicated that XAF1 expression was markedly altered in NSCLC tumor samples when compared to that found in normal lung tissues. Predominantly, XAF1 was downregulated in the tumors, except in never-smoker patients. In addition, XAF1 may also be important in the whole cell stress mechanism where the p53 status is crucial.
\end{abstract}

Correspondence to: Dr Luciene Schluckebier, Clinical Research Division, Instituto Nacional de Câncer (INCA), Rua André Cavalcanti $37,2^{\circ}$ andar, Rio de Janeiro, Brazil

E-mail: lucfontes@gmail.com

Present address: ${ }^{4} \mathrm{D}^{\prime} \mathrm{Or}$ Institute for Research and Education (IDOR), Rio de Janeiro, Brazil

Abbreviations: XAF1, XIAP-associated factor 1; HSF1, heat-shock transcription factor 1; NSCLC, non-small cell lung cancer; XIAP, $\mathrm{X}$-linked inhibitor of apoptosis protein; HSEs, heat shock response elements; GI, gastrointestinal cancer; CI, confidence interval; Nt, nucleotides; INCA, Instituto Nacional de Câncer; BNT-INCA, Brazilian National Tumor and DNA Bank

Key words: lung cancer, XIAP-associated factor 1, human, genes, $\mathrm{p} 53$, heat shock transcription factor 1 , carcinogenesis

\section{Introduction}

Lung cancer is the most lethal type of cancer accounting for nearly 1,600,000 deaths worldwide in 2012 (1). Non-small cell lung cancer (NSCLC) is the predominant histological type, accounting for $80-85 \%$ of all cases (2). Histological type and extension of disease at the time of diagnosis influence prognosis. Yet, even with the advent of new targeted therapies and improved methods for early diagnosis, patients with lung cancer have short-term survival (1). Highlighting biologic markers is essential to clarify malignant lung processes, to identify patient subtypes and thereby to improve the poor prognosis of lung cancer.

The apoptosis pathway has been extensively studied in cancer research since malignant cells have the ability to evade this pathway. The disruption in the balance between pro-survival and pro-death cascades could break the barrier to cancer (3). In this context, the inhibitors of apoptosis proteins comprise a range of molecules, which play a critical role in cell-acquired resistance to death. In many types of tumors, the levels of expression of certain molecules commonly appear upregulated, and one example is the X-linked inhibitor of apoptosis protein (XIAP) protein (4). XIAP-associated factor 1 (XAF1) is a pro-apoptotic protein and it was primarily identified as an antagonist of XIAP, counteracting XIAP anti-caspase activity (5). Data suggest a plethora of possible XAF1 functions favoring apoptosis either through survivin degradation (6), mitochondrial cytochrome $c$ release $(7,8)$, p53 stabilization $(9,10)$, as a modulator of cell cycle $\mathrm{G}_{2} / \mathrm{M}$ phase (11), as an inductor of autophagy by upregulating Beclin 1 (12), inhibition of the AKT pathway (12) or also inhibition of VEGF (13).

Loss of XAF1 has been observed in many types of tumors and is associated with increased malignant potential (9,13-21). Exceptionally, testicular germ cell tumors show XAF1 overexpression, which could be one of the reasons behind their extraordinary sensitivity to chemotherapy (22). In vitro assays have shown that restoration of XAF1 expression sensitizes cancer cells to apoptotic stimuli $(5,9)$.

Understanding the mechanism of XAF1 downregulation in tumors could be a promising strategy by which to introduce new agents capable of restoring XAF1 expression and improving drug response. There are a variety of processes 
under investigation. For example, epigenetic patterns altered within the promoter region of XAF1 genes have been identified in tumors. Hypermethylation of CpGs sites located in the $5^{\prime}$ proximal region was found to be associated with transcriptional silencing of XAF1 in gastric cancer $(14,23)$, urogenital (24) and colon (25) cancer cell lines. However, epigenetic modifications are extremely complex and other XAF1 associations have been observed. Heat-shock factor 1 (HSF1) belongs to a family of transcriptional factors involved in cellular response under stress conditions. Once activated, HSF1 homotrimerizes, translocates to the nucleus and binds to heat shock response elements (HSEs) to regulate the transcription of target genes (26). Notably, a functional HSF1-binding element was recognized in the XAF1 promoter gene and was found to be associated with the repression of XAF1 transcription (27). Wang et al reported that gastrointestinal cancer (GI) overexpressed HSF1 compared to normal tissues and the XAF1 expression was inversely correlated with HSF1 in GI cancer cell lines (27).

The tumor microenvironment can also provide abnormal conditions for cells. Dai et al reported that HSF1 may promote oncogenesis by facilitating cellular adaptation to the malignant lifestyle (26). HSF1 was also reported as a coadjuvant at the p53 transcriptional machinery. In response to DNA damage, HSF1 can complex with p53 and regulate p53-responsive genes, but only in wild-type p53 cells (28).

Recently, a link between XAF1 and p53 was demonstrated. The p53 responsive element was found within the promoter of the XAF1 gene and p53 was found to suppress the transcription of XAF1 (29). Zou et al confirmed that there is a direct and functional interaction between $\mathrm{p} 53$ protein and the XAF1 promoter (10). This interaction was found in wild-type p53, but not mutant p53 cells. Furthermore, there are no data integrating XAF1 and HSF1 expression and the p53 status in patient cohorts. Since there are limited studies performed in lung cancer patients (21), we investigated the XAF1 expression in a prospective cohort of NSCLC patients, and also lung cancer cell lines. Our data may contribute to the understanding of the potential role of XAF1 as a tumor-suppressor gene and its suggestive regulations.

\section{Patients and methods}

Primary tumor tissues and cancer cell lines. A total of 39 primary non-small cell lung tumor and their adjacent non-tumor tissues, were prospectively obtained by surgical resection at the Brazilian National Cancer Institute (INCA). Patients were recruited from January 2006 to January 2008. Inclusion criteria were primary resectable lung tumors, non-metastatic and non-small cell subtype. Pancoast tumors were excluded from our cohort. All patients enrolled provided informed consent before surgery. Tissue specimens were snap-frozen immediately and stored (until used) in liquid nitrogen according to the Brazilian National Tumor and DNA Bank (BNT-INCA) guidelines. Data regarding clinical and histopathological characteristics were collected from medical records based on the World Health Organization and 2009 tumor-node-metastasis (TNM) classification guidelines. Patients were classified according to smoking status: neversmokers, individuals who had smoked 100 cigarettes in their lifetime; former smokers, who had quit smoking for at least one year; current smokers, those who smoke $>100$ cigarettes and have also smoked for less than one year. As an indication of cumulative smoking exposure, pack-years were defined as the average number of packs smoked/day multiplied by years smoked. All patients received a detailed explanation concerning the study aims and procedures and a signed informed consent form was provided. The protocol was previously accepted by the Instituto Nacional de Cancer Institutional Review Board (Protocol 31/05).

Cell culture. NSCLC cell lines with different mutational statuses were kindly provided by Dr Giuseppe Giaccone (Free University Medical Center, Amsterdam, The Netherlands), H460 and A549; ACC-LC-94, ACC-LC-319 and Calu-1 cells were from Dr Takashi Takahashi (Center for Neurological Diseases and Cancer, Nagoya University Graduate School of Medicine, Japan); H820 and H1975 cells were from Dr Michael Peyton (Human Center for Therapeutic Oncology Research, University of Texas Southwestern Medical Center, TX, USA). Mutant cells for p53 included ACC-LC-94, ACC-LC-319, Calu-1 and H820. Except for H1975, all cell lines present $K$-ras mutation. For EGFR status only H1975 and H820 were mutated. Cells were cultured in RPMI-1640 medium supplemented with $10 \%$ fetal calf serum, containing penicillin/streptomycin/glutamine (Gibco-BRL, Grand Island, $\mathrm{NY}, \mathrm{USA}$ ) at $37^{\circ} \mathrm{C}$ under $10 \% \mathrm{CO}_{2}$.

RNA extraction and cDNA synthesis. Total RNA was isolated from cell lines or frozen tissues using TRIzol ${ }^{\circledR}$ (Invitrogen Life Technologies) and purified with Qiagen RNeasy kit (Qiagen, Hilden, Germany) according to the manufacturer's protocol. RNA concentrations were determined using NanoDrop ${ }^{\circledR}$ ND-1000 spectrophotometer. The RNA was reverse transcribed using SuperScript II Reverse Transcriptase (Invitrogen Life Technologies) according to the manufacturer's instructions. In summary, $1 \mu \mathrm{g}$ of total RNA was used to synthesize cDNA using oligo $(\mathrm{dT})_{15}$ (Promega, Madison, WI, USA) at $65^{\circ} \mathrm{C}$ for $5 \mathrm{~min}$, followed by incubation with the reverse transcriptase enzyme at $42^{\circ} \mathrm{C}$ for $50 \mathrm{~min}$, and inactivation at $70^{\circ} \mathrm{C}$ for $15 \mathrm{~min}$. The resulting complementary DNA was diluted in ultra-pure water and used in the real-time amplification reaction.

Quantitative real-time PCR. The mRNA levels of XAF1 were measured by real-time RT-PCR based on TaqMan ${ }^{\circledR}$ chemistry and quantified with an ABI PRISM 7500 Fast Sequence Detection system (Applied Biosystems, Foster City, CA, USA). An internal control gene, GAPDH, was used to normalize the mRNA levels. The XAF1 and GAPDH mRNA levels were assessed using pre-developed TaqMan ${ }^{\circledR}$ Gene Expression Assays part no. Hs00213882_m1 and 4310884E, respectively (Assay-on-Demand $^{\mathrm{TM}}$; Applied Biosystems). A commercially available cDNA derived from normal human lung tissue was used to compare normal lung XAF1 mRNA expression levels with the ones from different cell lines (Ambion's FirstChoice ${ }^{\circledR}$ PCR-Ready Human Lung cDNA; Applied Biosystems). The patient tumor samples were compared to their adjacent normal tissues. All primers and probes were allocated in exon-exon regions, thus, preventing the amplification of residual genomic DNA. Real-time PCR was performed in duplicate 
reactions using TaqMan ${ }^{\circledR}$ Fast Universal PCR Master Mix (Applied Biosystems). Instrument raw data (fluorescence) of all the samples was converted to threshold cycles by SDS 1.2 software (Applied Biosystems). All target gene amplification was normalized with their internal control gene expression $(\Delta \mathrm{Ct})$. To calculate the relative expression level, $\Delta \mathrm{Ct}$ tumor was compared with the $\Delta \mathrm{Ct}$ adjacent non-tumor tissue for patient samples. For the cell lines, comparison was made to a commercially normal human lung control. The relative expression value was $\log 2$-transformed for statistical analysis. The fold-change between samples and the human lung control represents the relative XAF1 expression in the cell lines. The fold-change between non-tumoral and tumoral tissues represents the relative expression in the patient cohort. Patients with loss of XAF1 expression were defined as tumors expressing a fold-change $1 / 5$ below the non-tumoral value.

Immunohistochemistry. The XAF1 and HSF1 proteins were evaluated by immunohistochemistry. Formalin-fixed paraffinembedded serial sections ( $3 \mu \mathrm{m}$ ) were mounted on glass slides (ImmunoSlide; EasyPath ${ }^{\circledR}$ São Paulo, SP, Brazil), dewaxed with xylene and gradually hydrated in ethanol. The slides were heated in a pressure cooker with a citrate buffer $(\mathrm{pH} 6,0)$ for antigen activation. After cooling, endogenous hydrogen peroxidase and unspecific proteins were blocked. Anti-XAF1 antibody (1:500; Abcam, Cambridge, MA, USA) and antiHSF1 antibody (1:100; Cell Signaling Technology, Beverly, MA, USA) were incubated at $37^{\circ} \mathrm{C}$ for $45 \mathrm{~min}$ and at $4^{\circ} \mathrm{C}$ overnight. Then, the immunoslides were blocked with Primary Block and secondary antibody treatment (Novolink Polymer; Novocastra, Newcastle, UK). Immunostaining was carried out with diaminobenzidine solution and counterstained with hematoxylin.

In both analyses, the score was determined using nuclear staining. XAF1 expression was scored using two measures: the rate of cells stained classified as $1(<5 \%), 2(5-24 \%)$, 3 (25-49\%), $4(50-74 \%)$ and 5 (>75\%); and staining intensity graded as 1 (weak) and 2 (strong). The final score was calculated by multiplying the area stained and the intensity resulting in three expression levels: low (1-3); moderate (4-6); and high (8-10) (30). Reduction in XAF1 protein was considered when samples with high expression levels became moderate or low.

HSF1 scoring was based on staining intensity with 0 indicating no staining, 1 indicating low-level, and 2 indicating strong staining. Cases with no detectable HSF1, or only cytoplasmatic reaction were defined HSF1-negative and cases with low or strong nuclear staining were defined HSF1-positive (36).

Mutation analysis. TP53 mutation analysis was performed according to the standard protocol at the International Agency for Research on Cancer (IARC) (http://www-p53.iarc.fr/ Download/TP53_DirectSequencing_IARC.pdf). Approximately $25 \mathrm{mg}$ of fresh tissue was processed to obtain DNA using the QIAamp DNA Mini kit (Qiagen) according to the manufacturer's protocol. TP53 mutation was assessed by direct sequencing using primers described as follows: 5'-tgttcactt gtgccctgact-3' and 5'-tctctgggaggaggggttaa-3' (exon 5-6); 5'-ctt gccacaggtctccccaa-3' and 5'-tctgcttgccgctgacccet-3' (exon 7); $5^{\prime}$-ttgggagtagatggagccet-3' and $5^{\prime}$-aaagtttccagtctaacact-3' (exon 8-9). Sequencing reaction was carried out using BigDye ${ }^{\circledR}$
Terminator v1.1 Cycle Sequencing kit. Before analysis, purification of the sequencing reaction products was carried out using the sequencing service (IARC) with 96-well MultiScreen filtration plates (G50; Pharmacia/Millipore, Billerica, MA, USA). PCR products were analyzed using a 16-capillary automated sequencer (ABI PRISM ${ }^{\circledast} 3100$ Genetic Analyzer; Applied Biosystems), based on the Sanger method. Chromatograms were semi-automatically analyzed by visual inspection of sequences imported into the sequence analysis software using the reference sequence, NC_000017.9, from GenBank (http://www-p53.iarc.fr/TP53sequence NC_000017-9.html). Variations were checked with the mutation validation tool available at IARC at http://www-p53. iarc.fr/Mutation ValidationCriteria.asp. This tool allowed us to check whether the variation is a known polymorphism or a mutation, and provided frequency and functional data as reported in the IARC TP53 database (http://www-p53.iarc.fr).

Statistical analysis. Data analysis was conducted using Statistical Package for Social Sciences (SPSS) version 13.0 software. Differences between XAF1 expression in cell samples were evaluated by Student's t-test. Paired adjacent non-tumoral and tumoral samples were compared by McNemar test. The Chi-square test was applied to evaluate the univariative correlations between XAF1 expression and the clinicopathological parameters. Kaplan-Meier estimates were calculated to detail differences in recurrence-free and overall survival by XAF1 expression and were tested for statistical significance using the log-rank test. All p-values were twotailed and $\mathrm{p}<0.05$ was considered to indicate a statistically significant result.

\section{Results}

Depletion of XAF1 mRNA expression occurs in different lung cancer cell lines. To investigate the potential role of XAF1 as a tumor-suppressor gene in lung tumorigenesis, we characterized the XAF1 mRNA expression levels in a variety of lung cancer cell lines. The cDNA derived from normal lung human tissue was used as a reference to compare XAF1 expression in cell lines in relation to normal lung tissue. All cells showed a significant reduction in the XAF1 mRNA expression level when compared to the normal lung control (Fig. 1). The levels of XAF1 mRNA were low to non-existent in the H460, A549, ACC-LC-94 and ACC-LC-319 cells, while in the mutant EGFR cells (H820 and H1975) and TP53-deleted cell (Calu-1), the levels were higher than that noted in the other cells (Fig. 1).

Depletion of XAF1 expression is correlated with increased malignant potential in patient samples. After obtaining the expression levels of XAF1 in the cell lines, we conducted analysis using our patient cohort. Clinicopathological characteristics of 39 patients with NSCLC treated at our institute are described in Table I. The median follow-up was 63 months. During this period, 16 patients died, and 19 had progressive disease.

Primary lung specimens were evaluated in 39 matched sets of adjacent non-tumor and tumor tissues. All patients had a markedly tumor-specific low expression of XAF1 mRNA with a mean of 0.39 [95\% confidence interval (CI), 0.28-0.49) in the 


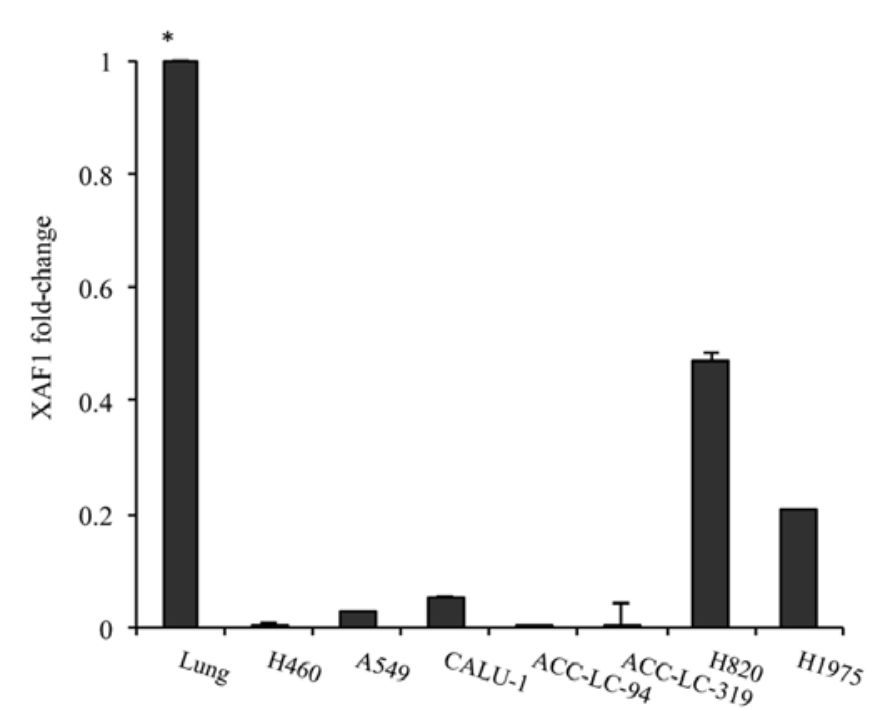

Figure 1. XAF1 mRNA expression levels were determined in a lung cancer cell line panel and in a non-cancer tissue lung control by real-time RT-PCR and were normalized to GAPDH and compared to a commercially available normal lung tissue (Ambion's FirstChoice ${ }^{\circledR}$ PCR-Ready Human Lung cDNA; Applied Biosystems); ${ }^{*} \mathrm{p}<0.001$ by Student's t-test.

non-tumor and 0.09 (95\% CI, 0.05-0.15) in the tumor tissue group (Fig. 2A). The relative expression values indicated that almost all patients had a reduction in XAF1 expression values in the tumor and only two showed tumor expression higher than that noted in the matched tissue (Fig. 2B).

Regarding protein levels, a reduction in XAF1 expression was observed in lung tumor samples upon immunohistochemical analyses performed using the anti-XAF1 antibody. In contrast, high XAF1 protein expression was found predominantly in non-tumor tissues (Fig. 3A and B). When paired samples were compared, with exception of one sample in which increased XAF1 protein expression was observed and another which maintained a high score, all other samples significantly showed a decrease in the expression of XAF1 protein levels after malignant transformation (McNemar test; $\mathrm{p}=0.001)$ (Fig. 4A and B). In order to summarize and better visualize the results obtained from the XAF1 expression experiments according to IHC score, two different plots are shown in Fig. 4.

XAF1 depletion is correlated with HSF1 protein expression in lung tissues. A functional HSF1-binding element was recognized in the XAF1 promoter gene and was related to the repression of XAF1 transcription (27). Therefore, in order to investigate whether XAF1 downregulation in lung tumors is associated with activated HSF1, the HSF1 protein was evaluated in all tumoral/adjacent non-tumoral matched tissues via immunohistochemistry. HSF1 protein can appear in both the cytoplasm and nucleus, but the active form is localized only in the nucleus. In all tumor specimens, strong nuclear staining of HSF1 was observed. In contrast, we did not observe HSF1 expression in the adjacent non-tumoral tissues (Fig. 5).

XAF1 protein reduction occurs in wild-type p53 tumors. Published data (29) have shown that XAF1 is a target gene of $\mathrm{p} 53$, since it carries a $\mathrm{p} 53$ responsive element within the
Table I. Clinicopathological characteristics of the study cohort.

\begin{tabular}{|c|c|}
\hline Characteristics & Data \\
\hline NSCLC patients, n (\%) & $39(100)$ \\
\hline \multicolumn{2}{|l|}{ Age (years) } \\
\hline Median (range) & $62(41-79)$ \\
\hline \multicolumn{2}{|l|}{ Sex, n $(\%)$} \\
\hline Male & $22(56.4)$ \\
\hline Female & $17(43.6)$ \\
\hline \multicolumn{2}{|l|}{ Pathological TNM stage, n (\%) } \\
\hline I & $22(56.4)$ \\
\hline II & $9(23.1)$ \\
\hline IIIA & $8(20.5)$ \\
\hline \multicolumn{2}{|l|}{ Tumor size (cm) } \\
\hline Median (range) & $5.0(2.3-16.0)$ \\
\hline \multicolumn{2}{|l|}{ Nodal invasion, n (\%) } \\
\hline $\mathrm{N}_{0}$ & $28(71.8)$ \\
\hline $\mathrm{N}_{1}$ & $5(12.8)$ \\
\hline $\mathrm{N}_{2}$ & $6(15.4)$ \\
\hline \multicolumn{2}{|l|}{ Histologic subtype, n (\%) } \\
\hline Squamous cell carcinoma & $15(38.5)$ \\
\hline Adenocarcinoma & $24(61.5)$ \\
\hline \multicolumn{2}{|l|}{ Tumor grade, n (\%) } \\
\hline Well-differentiated & $4(10.3)$ \\
\hline Moderately differentiated & $25(64.1)$ \\
\hline Poorly differentiated & $8(20.5)$ \\
\hline Missing & $2(5.1)$ \\
\hline Adjuvant therapy, n (\%) & $15(38.5)$ \\
\hline Chemotherapy & $4(10.2)$ \\
\hline \multicolumn{2}{|l|}{ Radiotherapy } \\
\hline No & $20(51.3)$ \\
\hline \multicolumn{2}{|l|}{ Smoking status, n (\%) } \\
\hline Smoker & $21(53.8)$ \\
\hline Former-smoker & $15(38.5)$ \\
\hline Never-smoker & $3(7.7)$ \\
\hline Median follow-up (months) & 63 \\
\hline Recurrence, n (\%) & $19(48.7)$ \\
\hline Deaths, n (\%) & $16(41.0)$ \\
\hline Missing, $\mathrm{n}(\%)$ & $4(10.3)$ \\
\hline
\end{tabular}

NSCLC, non-small cell lung cancer; TNM, tumor-node-metastasis.

XAF1 promoter region. In addition, the presence of wild-type p53 was shown to influence the transcriptional repression of XAF, whereas in mutated p53 cells this did not occur (29). Following these results, we decided to analyze whether XAF1 reduction could have an association with TP53 mutational status, by comparing the score levels of XAF1 protein expression noted in Fig. 4 with the p53 mutational status in our patient cohort. We observed that in all wild-type p53 patients, except one, there was a loss in XAF1 protein expression in the 


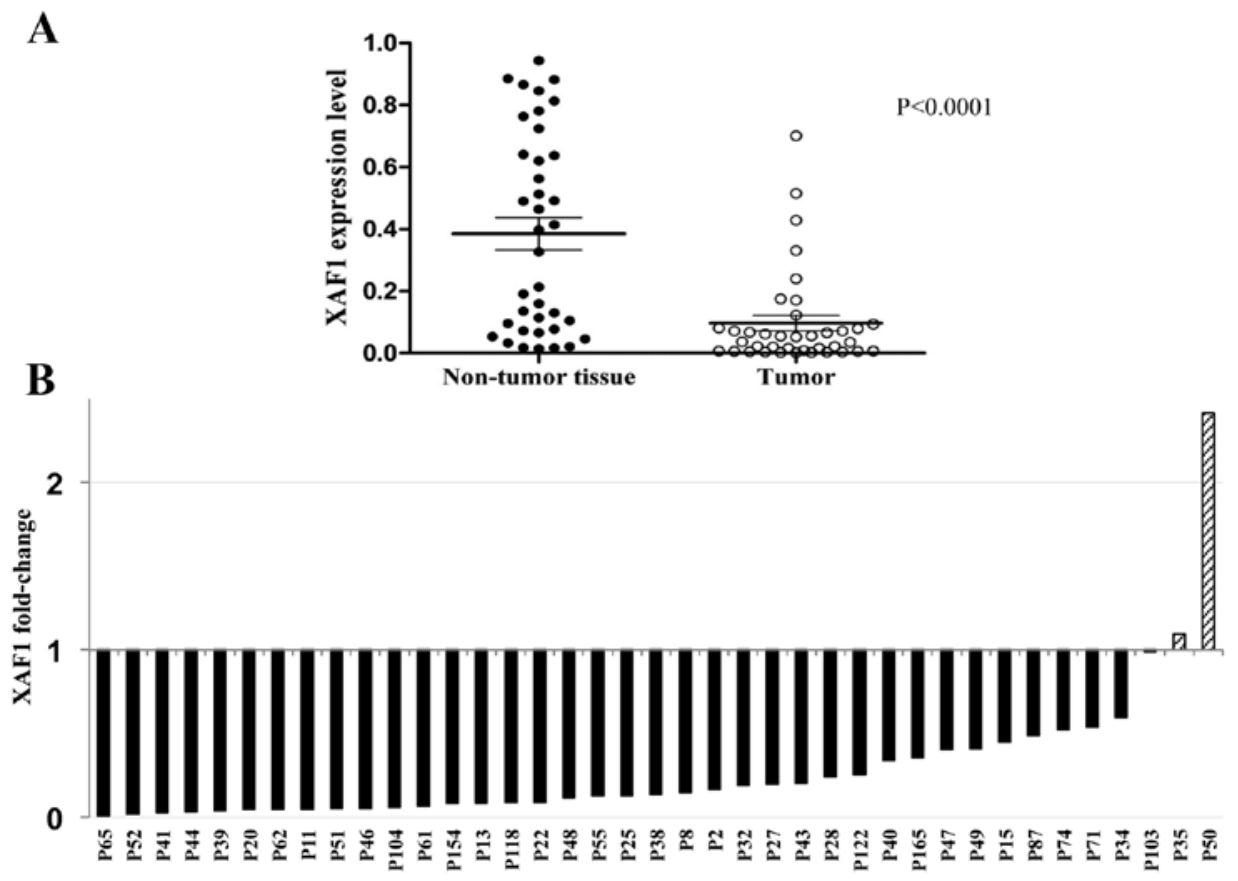

Figure 2. XAF1 mRNA expression in NSCLC patients. (A) Significant low expression in lung tumor specimens by Wilcoxon test (p<0.0001). (B) Relative expression levels for each tumor sample shown as a fold-change relative to its own adjacent non-tumor sample, in which the value was considered equal to one. Black bars represent patients with low tumor expression and streaked bars show tumor tissue having higher XAF1 levels than their paired non-tumor tissue.

A

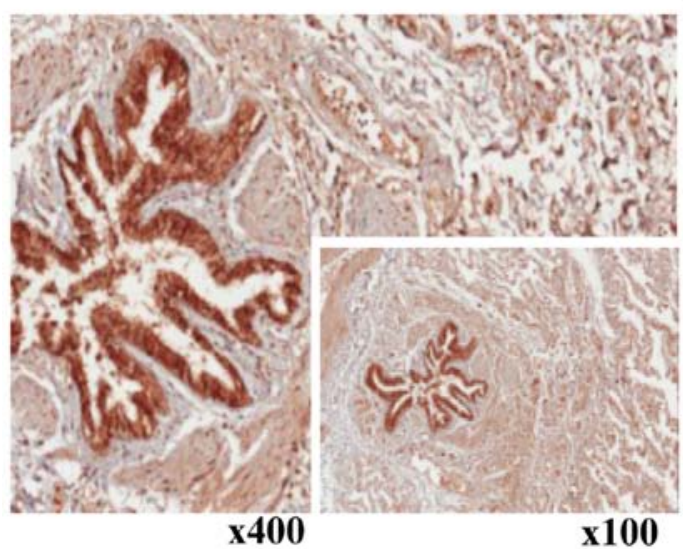

B

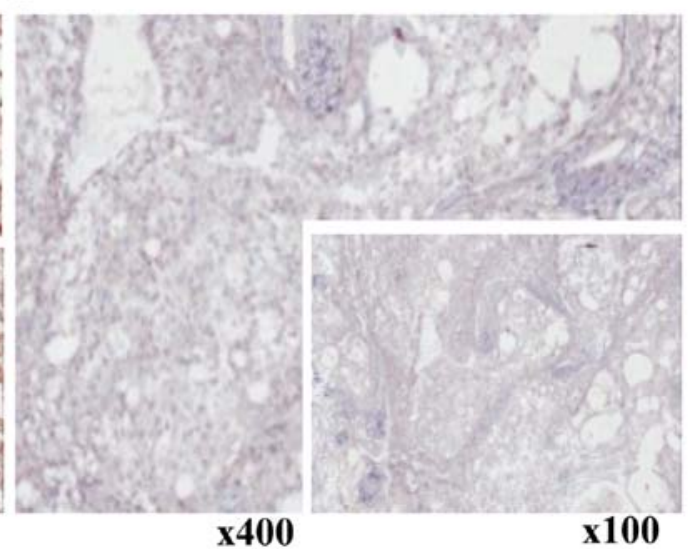

Figure 3. Immunohistochemical staining of XAF1 marker in NSCLC tissue. XAF1 protein expression was observed in the adjacent non-tumor vs. the tumor tissue (magnifications, $\mathrm{x} 400$ and x100) using the anti-XAF1 antibody (1:500). (A) Adjacent non-tumor lung tissue. (B) Lung tumor tissue. The method used to score XAF1 expression is described in the Materials and methods section.

A

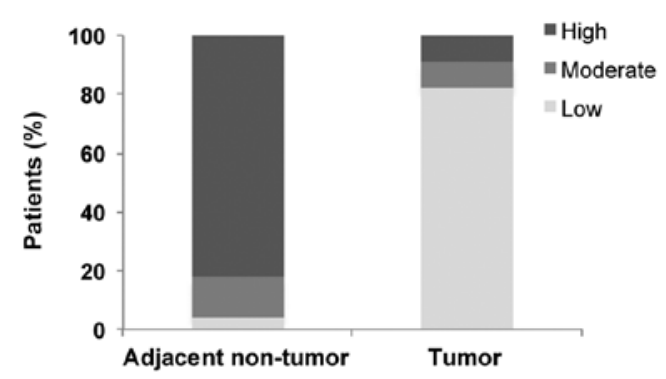

B

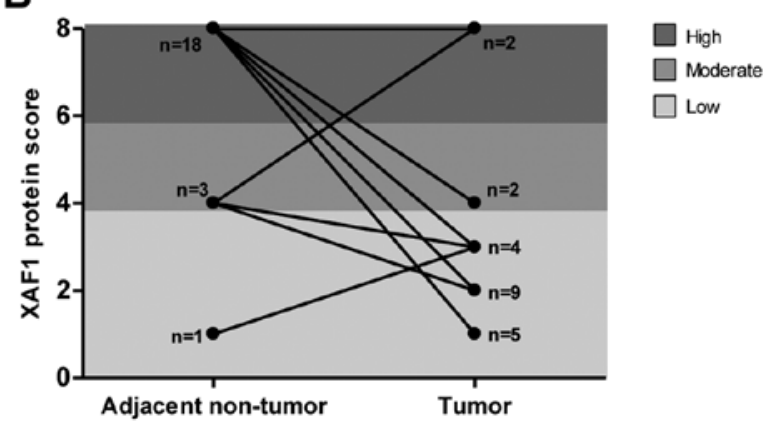

Figure 4. Immunohistochemical results comparing XAF1 expression levels in adjacent non-tumor vs. tumor tissues. (A) Patients are grouped by score staining. (B) Patients are scrutinized by their expression changes between non-tumor and tumor tissues. 
A

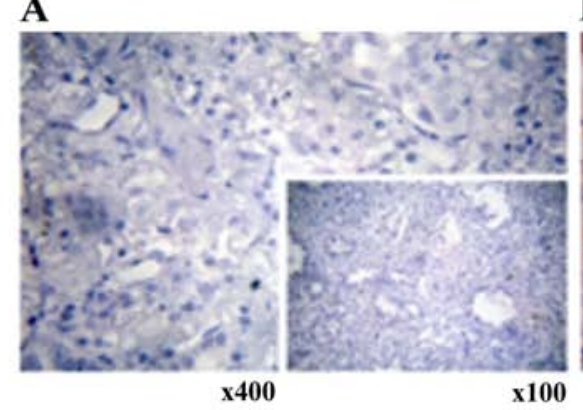

B

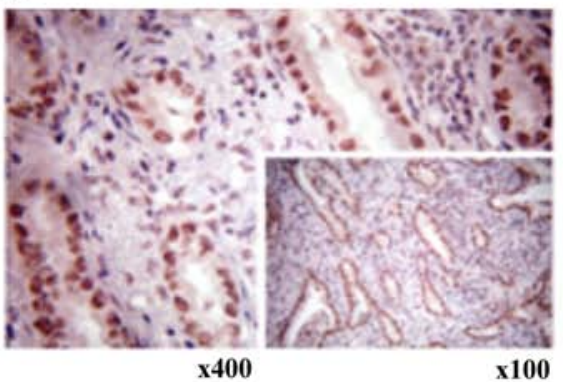

C

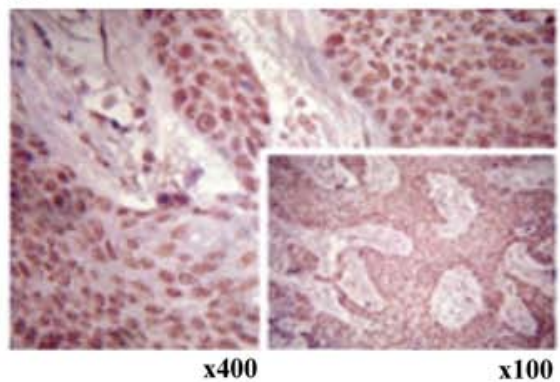

Figure 5. Expression of HSF1 protein by immunohistochemical analysis (magnifications, x400 and x100) using the anti-HSF1 antibody. (A) Adjacent nontumor lung tissue. (B) Well-differentiated lung adenocarcinoma. (C) Moderately differentiated squamous cell lung carcinoma.

Table II. Correlation between XAF1 protein losses and mutational status of the TP53 gene in NSCLC tumor tissues.

\begin{tabular}{lcc}
\hline & \multicolumn{2}{c}{ Loss of XAF1 protein } \\
\cline { 2 - 3 } TP53 status & Yes & No \\
\hline Wild-type & 13 & 1 \\
Mutated & 3 & 4 \\
\hline
\end{tabular}

$\mathrm{p}=0.02$. XAF1, XIAP-associated factor 1 ; NSCLC, non-small cell lung cancer.

tumor tissue compared to that noted in the adjacent non-tumor tissue (Table II). Nevertheless, we did not observe the same pattern when comparing the mutant p53 status and XAF1 mRNA level between specimens. Regarding mutation types, we did not observe a specific pattern. The patients from our cohort showed different TP53 mutations and also deletions (data not shown). Not all 39 patients had obtained results due to technical difficulties related to the sample quality.

Correlation between clinicopathological characteristics, prognosis and XAF1 expression. Clinicopathological characteristics and prognosis were correlated according to XAF1 tumor expression as shown in Table III. Expression levels of XAF1 appeared to be independent of sex, pathological stage, tumor size, nodal invasion and histological subtype. However, a correlation was noted between XAF1 reduction and age and undifferentiated tumor grade $(\mathrm{p}<0.01)$. Patients in the group of XAF1 depletion tended to have a poor differentiated histological grade.

The levels of XAF1 expression were also analyzed according to smoking behavior. Tumors from 2 out of 3 neversmoker patients, presented the highest XAF1 expression in the entire tumor cohort, both at the mRNA and protein levels. In addition, the frequency of XAF1 reduction was higher in the group of smoker patients than in the group of former- andnever smokers $(\mathrm{p}=0.05)$.

In order to further investigate the clinicopathological characteristics, we compared XAF1 expression levels with the risk of tumor-recurrence or tumor-related death and the data were analyzed by Kaplan-Meier estimates. The result indicated that
Table III. Correlation between XAF1 mRNA losses and clinicopathological parameters in the NSCLC patients.

\begin{tabular}{|c|c|c|c|}
\hline \multirow{2}{*}{$\begin{array}{l}\text { Clinicopathological } \\
\text { characteristics }\end{array}$} & \multicolumn{2}{|c|}{ XAF1 losses } & \multirow[b]{2}{*}{ P-value } \\
\hline & Yes, n (\%) & No, n $(\%)$ & \\
\hline Age (years) & & & $0.01^{\mathrm{a}}$ \\
\hline$\leq 60$ & $14(93.3)$ & $1(6.7)$ & \\
\hline$>60$ & $11(45.8)$ & $13(54.2)$ & \\
\hline Sex & & & 0.19 \\
\hline Male & $12(54.5)$ & $10(45.5)$ & \\
\hline Female & $13(76.5)$ & $4(23.5)$ & \\
\hline Smoking status & & & $0.05^{\mathrm{a}}$ \\
\hline Never-smoker & $0(0)$ & $3(100)$ & \\
\hline Former-smoker & $11(73.3)$ & $4(26.7)$ & \\
\hline Smoker & $14(66.7)$ & $7(33.3)$ & \\
\hline Pathological TNM stage & & & 0.48 \\
\hline I & $14(63.6)$ & $8(38.1)$ & \\
\hline II & $6(66.7)$ & $3(33.3)$ & \\
\hline III & $6(75.0)$ & $2(25)$ & \\
\hline Tumor size (cm) & & & 0.80 \\
\hline$\leq 5$ & $14(63.6)$ & $8(36.4)$ & \\
\hline$>5$ & $11(73.3)$ & $6(26.7)$ & \\
\hline Nodal invation & & & 0.42 \\
\hline Positive & $8(72.7)$ & $3(27.3)$ & \\
\hline Negative & $18(64.3)$ & $10(35.7)$ & \\
\hline Histological subtype & & & 0.49 \\
\hline Squamous cell & $10(66.7)$ & $5(33.3)$ & \\
\hline $\begin{array}{l}\text { Adenocarcinoma } \\
\text { (differentiated) }\end{array}$ & $14(58.3)$ & $10(41.7)$ & \\
\hline Tumor grade & & & $0.01^{\mathrm{a}}$ \\
\hline Well & $0(0)$ & $4(100)$ & \\
\hline Moderate & $19(76)$ & $6(24)$ & \\
\hline Poor & $5(62.5)$ & $3(37.5)$ & \\
\hline
\end{tabular}

XAF1, XIAP-associated factor 1; NSCLC, non-small cell lung

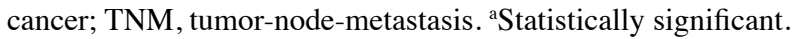

there were no significant associations in higher XAF1 losses and recurrence-free survival and overall survival (Fig. 6). 
A

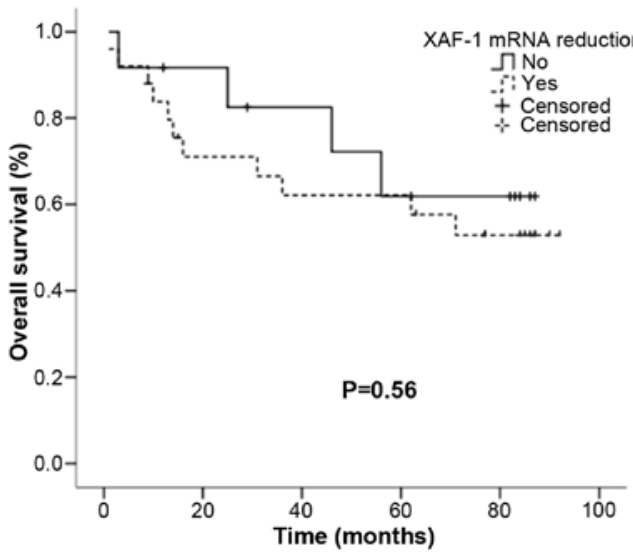

B

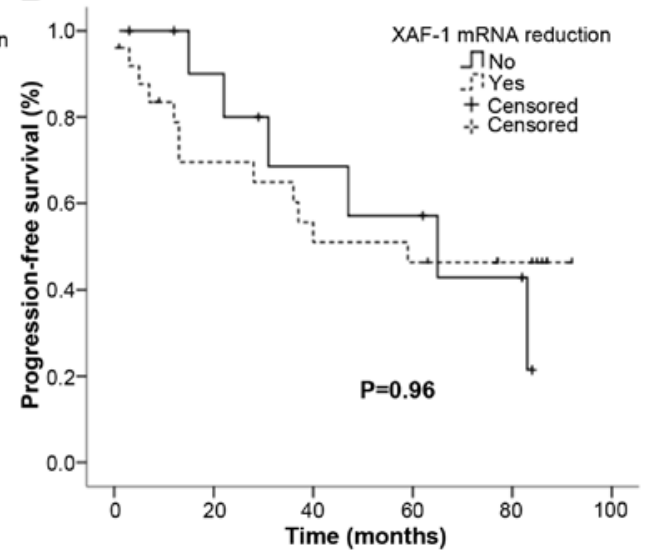

Figure 6. Kaplan-Meyer estimates of (A) overall survival and (B) progression free-survival in patients according to a reduction or not in XAF1 mRNA level (reduction was considered as the expression in the tumor tissue five times less than the level in the adjacent non-tumor paired tissue). In both curves, tick marks on the survival curves indicate censoring of data.

\section{Discussion}

The process of lung carcinogenesis is still not well understood and several studies have tried to investigate target molecules to improve therapy and survival. A particular molecule called XAF1, which belongs to the apoptosis pathway, was investigated by us. The putative tumor-suppressor gene XAF1 has been found underexpressed in various cancer tissues and cell lines and, in addition, data generated elsewhere showed that restoration of its expression could increase sensitivity to apoptotic stimuli (14-21,30).

Low expression of XAF1 was observed in squamous cell lung cancer (21). In the present study, we identified low expression of XAF1 in NSCLC cells lines compared to that noted in normal lung (Fig. 1). However, to the best of our knowledge, this is the first study to describe the same pattern in both lung adenocarcinoma cell lines and patient specimens.

Despite no significant evidence in prognosis (Fig. 6), our cohort showed an association between XAF1 and increased malignancy. An association between reduced XAF1 and a higher histopathological grade was observed in our tumor specimens (Fig. 2) corroborating the results of previous studies $(15,21,31-33)$. This may reinforce the potential role of XAF1 in lung tumor progression. Restoration of XAF1 could be a target mechanism to suppress malignant progression in the lung, as described in the literature for other tissue types. To that end a better understanding of the mechanisms leading to its downregulation is warranted. The first evidence for a possible cause of downregulation has been focused in hypermethylated regions at the XAF1 promoter gene (14). Therefore, we explored hypermethylation of $\mathrm{CpG}$ sites near the 5 ' proximal region ( -2 to $-246 \mathrm{nt})$ that appeared strongly correlated with transcriptional silencing. We frequently observed the same profile in both non-tumor and tumor tissues by the methylation-specific PCR technique (data not shown). In order to investigate specific $\mathrm{CpG}$ sites and quantify the methylated percentage, we performed quantitative real-time PCR. One primer covered proximal CpGs sites -3 and -4 and the second one covered -5 to $-7 \mathrm{CpG}$ sites. After evaluating the methylation pattern in all matched paired lung tissues, we observed that $13(31 \%)$ tumor tissues were hypermethylated (data not shown). The percentage of methylation varied from 2 to $30 \%$ in the $\mathrm{CpG}$ site -3 and -4 and from 2 to $88 \%$ in $\mathrm{CpG}$ site -5 to -7 . When CpG -3 and -4 site appeared hypermethylated, the CpG site -5 to -7 was usually highlighted too. Almost all cases of non-tumor adjacent tissues appeared unmethylated or $<1 \%$ methylated (data not shown). Our intention was to explore methylated areas with possible useful techniques applicable to the clinic setting, such as PCR. Since the XAF1 promoter region does not contain defined $\mathrm{CpG}$ islands but instead it contains $\mathrm{CpG}$ sites too closely, we found it difficult to deeply explore methylated areas using these techniques.

Meanwhile, the silencing of XAF1 in tumors has been investigated by other groups. Wang et al observed a functional HSF1-binding element (HSE/XAF1) located at $-862 /-821$ of the XAF1 gene. They showed that HSF1 could repress XAF1 transcription and this could be reversed by blocking HSF1 binding (23). Under oncogenic stimulus, HSF1 could affect cell transformation, proliferation, signal transduction and metabolic process in favor of survival. Therefore, HSF1 could respond to oncogenic stimuli and add on the global network to support tumorigenesis (26). HSF1 can also have a dual action under stressful conditions. In normal cells it was described as a molecule, which protects cells from pathophysiological conditions such as hypoxia, thermal injury and age-related neurodegeneration $(34,35)$. Since normal physiology is altered in the tumor microenvironment, HSF1 could also enhance malignancy levels. Notably, breast cancer containing high HSF1 was associated with poor prognosis (36). Another study showed that $\mathrm{HSF}^{-/}$mice presented superior survival to $\mathrm{HSF}^{+/+}$mice after tumor induction, as well as enhanced resistance to tumor formation (26).

In the present study, we investigated HSF1 protein and we observed that higher levels of HSF1 protein were translocated to the nucleus (where HSF1 is active) in tumor tissues (Fig. 5). Moreover, absence of expression was detected in non-tumor paired tissues indicating that HSF1 may be activated during the lung carcinogenesis process. This is consistent with the findings in gastric and colon cancer, where Li et al observed higher expression of HSF1 in gastrointestinal cancer tissues 
than in normal tissues (37). They also showed that stress stimuli of gastrointestinal cancer cell lines could upregulate HSF1 expression, but inversely downregulate XAF1 expression (37). In our immunohistochemical results (Figs. 3 and 5), a reduction in XAF1 expression was observed in lung tumor samples (Fig. 3), whereas a strong nuclear staining of HSF1 was observed in the tumor tissues (Fig. 5). Since HSF1 was shown to downregulate XAF1 expression in tumors, it may be informative to develop a selective HSF1 inhibitor in order to observe whether the levels of XAF1 could be restored in cancer cells. One difficulty which must be overcome is the fact that HSF1 is highly versatile, involved in numerous stress and non-stress related cell processes (38). Furthermore, it is also an important link for the translational machinery, since it was shown that a block in translation in cancer cells resulted in inhibition of HSF1 binding to its target genes (39). Thus, another possible way to block HSF1 activity may be to interfere with the ribosomal function in the cancer cells.

Logan et al supports the idea of HSF1 implicated in cell conjecture via p53-regulated transcription. It is well known that p53 can predominantly act in favor of cell cycle arrest and apoptosis under DNA damage. However it can also act as a pro-cell survival factor depending on the extent of damage or stress duration. Under genotoxic stress, evidence shows that p53 transcriptional activity is dependent upon HSF1 interaction and that HSF1 also facilitates phosphorylation of p53 serine residue 6 and 15 via the Chk1/ATR complex (28). Although these findings indicate pro-apoptotic effects, the author advocates that in response to oncogenic activation, HSF1 may redirect its function via p53 to promote cell survival and tumorigenesis (28).

$\mathrm{XAF} 1$ has been reported as a target gene for $\mathrm{p} 53$ since it carries a p53 responsive element (-86 to $-95 \mathrm{nt}$ ) within the XAF1 promoter region (29). In cancer cells, the presence of wild-type 553 could lead to transcriptional repression of XAF1 while in mutated p53 cells this did not occur (29). Byun et al reported for the first time the inverse correlation between loss of XAF1 and p53 mutations in gastric cells and tumors (14), but to date there are scarce studies investigating other cohorts. In the present study, p53-deleted cells had higher XAF1 expression than wild-type ones indicating a possible feedback loop mechanism (Fig. 1). In lung tumor specimens, we observed a reduction in XAF1 expression compared to the paired non-tumoral adjacent tissue indicating that XAF1 expression could be influenced by the level of tumorigenesis (Fig. 2B). In our wild-type 53 patients, we observed a reduction in XAF1 protein levels in tumor samples when compared to adjacent non-tumor tissue (Table II). In contrast, we did not observe the same pattern in mutant p53 specimens (Table II). Although this could be further confirmed by increasing the cohort number, one possible reason for this result could be that XAF1 may be upregulated in order to compensate for mutant $\mathrm{p} 53$, indicating a possible feedback-loop mechanism. It was recently observed that XAF1 forms a positive feedback loop with p53 by acting as a molecular switch in p53-decision making and that different isoforms of XAF1 have different functions $(10,40)$.

We also observed that all never-smoker patients did not lose XAF1 expression and among them, two exhibited a higher level of XAF1 in the tumor tissue than that in the adjacent tissue (Table III). Conversely, XAF1 expression was reduced in smokers, showing that XAF1 expression could be associated with smoking (Table III; $\mathrm{p}=0.05$ ). Moreover, cells harboring EGFR mutation (an alteration more commonly observed in never-smokers) also had higher XAF1 expression when compared to EGFR wild-type cells. Altogether, these findings are congruent with the current distinction between tumors from smokers and never-smokers. In the mid 2000's, non-smokingrelated lung cancer became an independent disease from the well-established lung cancer in smokers (41). Different studies indicated a heavier mutation burden and a greater perturbation of gene expression levels in smoking-related lung cancer than in non-smoking, and different driver genes were identified in non-smoker vs. smoker tumors $(42,43)$. In addition, distinct characteristics were observed in non-smoker patients, which could vary according to sex, histological type and ethnic origin. For example, most occurrences were in woman, Asian people and the predominant histological type was adenocarcinoma (41). Our findings should be further validated in a larger cohort of never-smoker patients.

In conclusion, our results indicated that XAF1 expression is altered in NSCLC tumor samples when compared to normal tissue and that the XAF1 status was influenced by different clinicopathological characteristics, such as smoking, EGFR and TP53 mutation status. However, no significant associations were observed for both tumor-recurrence or tumor-related death. The limited sample size could have influenced these results, since patients in the group of with lack of XAF1 tended to have poorly differentiated histological grade. It may be interesting to validate our findings in a larger cohort, including stage IV patients. In addition, XAF1 not only plays a role as a tumor suppressor but it is also important in the entire cell stress mechanism where the p53 status is crucial. It remains to be determined which molecules belonging to different signaling cascades may mediate XAF1 activation or downregulation in lung cancer. Moreover, further understanding of the molecular mechanisms underlying HSF1 must to be increased, and it may be valuable to determine whether HSF1 may be a therapeutic target by which to mediate XAF1 levels in lung cancer cells.

\section{Acknowledgements}

The present study was supported by the Ary Frauzino Cancer Foundation and the Coordination for the Improvement of Higher Education Personnel (CAPES). We would like to thank all the patients involved.

\section{References}

1. Ferlay J, Soerjomataram I, Ervik M, Dikshit R, Eser S, Mathers C, Rebelo M, Parkin DM, Forman D and Bray F: GLOBOCAN 2012 v1.0, Cancer Incidence and Mortality Worldwide: IARC CancerBase No. 11 (Internet). International Agency for Research on Cancer, Lyon, France, 2013. http:// globocan.iarc.fr. Accessed January, 23, 2015.

2. Govindan R, Page N, Morgensztern D, Read W, Tierney R, Vlahiotis A, Spitznagel EL and Piccirillo J: Changing epidemiology of small-cell lung cancer in the United States over the last 30 years: Analysis of the surveillance, epidemiologic, and end results database. J Clin Oncol 24: 4539-4544, 2006.

3. Hanahan D and Weinberg RA: Hallmarks of cancer: The next generation. Cell 144: 646-674, 2011.

4. Holcik M, Gibson H and Korneluk RG: XIAP: Apoptotic brake and promising therapeutic target. Apoptosis 6: 253-261, 2001. 
5. Liston P, Fong WG, Kelly NL, Toji S, Miyazaki T, Conte D, Tamai K, Craig CG, McBurney MW and Korneluk RG: Identification of XAF1 as an antagonist of XIAP anti-caspase activity. Nat Cell Biol 3: 128-133, 2001.

6. Arora V, Cheung HH, Plenchette S, Micali OC, Liston P and Korneluk RG: Degradation of survivin by the $\mathrm{X}$-linked inhibitor of apoptosis (XIAP)-XAF1 complex. J Biol Chem 282: 26202-26209, 2007.

7. Xia Y, Novak R, Lewis J, Duckett CS and Phillips AC: Xaf1 can cooperate with TNFalpha in the induction of apoptosis, independently of interaction with XIAP. Mol Cell Biochem 286: 67-76, 2006 .

8. Straszewski-Chavez SL, Visintin IP, Karassina N, Los G, Liston P, Halaban R, Fadiel A and Mor G: XAF1 mediates tumor necrosis factor-alpha-induced apoptosis and $\mathrm{X}$-linked inhibitor of apoptosis cleavage by acting through the mitochondrial pathway. J Biol Chem 282: 13059-13072, 2007.

9. Lee MG, Huh JS, Chung SK, Lee JH, Byun DS, Ryu BK, Kang MJ, Chae KS, Lee SJ, Lee CH, et al: Promoter CpG hypermethylation and downregulation of XAF1 expression in human urogenital malignancies: Implication for attenuated p53 response to apoptotic stresses. Oncogene 25: 5807-5822, 2006.

10. Zou B, Chim CS, Pang R, Zeng H, Dai Y, Zhang R, Lam CS, Tan VP, Hung IF, Lan HY, et al: XIAP-associated factor 1 (XAF1), a novel target of p53, enhances p53-mediated apoptosis via post-translational modification. Mol Carcinog 51: 422-432, 2012.

11. Wang J, Gu Q, Li M, Zhang W, Yang M, Zou B, Chan S, Qiao L, Jiang B, Tu S, et al: Identification of XAF1 as a novel cell cycle regulator through modulating $\mathrm{G}_{2} / \mathrm{M}$ checkpoint and interaction with checkpoint kinase 1 in gastrointestinal cancer. Carcinogenesis 30: 1507-1516, 2009.

12. Sun PH, Zhu LM, Qiao MM, Zhang YP, Jiang SH, Wu YL and Tu SP: The XAF1 tumor suppressor induces autophagic cell death via upregulation of Beclin-1 and inhibition of Akt pathway. Cancer Lett 310: 170-180, 2011.

13. Zhu LM, Shi DM, Dai Q, Cheng XJ, Yao WY, Sun PH, Ding Y, Qiao MM, Wu YL, Jiang SH, et al: Tumor suppressor XAF1 induces apoptosis, inhibits angiogenesis and inhibits tumor growth in hepatocellular carcinoma. Oncotarget 5: 5403-5415, 2014.

14. Byun DS, Cho K, Ryu BK, Lee MG, Kang MJ, Kim HR and Chi SG: Hypermethylation of XIAP-associated factor 1, a putative tumor suppressor gene from the $17 \mathrm{p} 13.2$ locus, in human gastric adenocarcinomas. Cancer Res 63: 7068-7075, 2003.

15. Chung SK, Lee MG, Ryu BK, Lee JH, Han J, Byun DS, Chae KS Lee KY, Jang JY, Kim HJ, et al: Frequent alteration of $X A F 1$ in human colorectal cancers: Implication for tumor cell resistance to apoptotic stresses. Gastroenterology 132: 2459-2477, 2007.

16. Shibata T, Noguchi T, Takeno S, Gabbert HE, Ramp U and Kawahara K: Disturbed XIAP and XAF1 expression balance is an independent prognostic factor in gastric adenocarcinomas. Ann Surg Oncol 15: 3579-3587, 2008.

17. Zhang F, Wu LM, Zhou L, Chen QX, Xie HY, Feng XW and Zheng SS: Predictive value of expression and promoter hypermethylation of $X A F 1$ in hepatitis B virus-associated hepatocellular carcinoma treated with transplantation. Ann Surg Oncol 15: 3494-3502, 2008.

18. Sakemi R, Yano H, Ogasawara S, Akiba J, Nakashima O Fukahori S, Sata M and Kojiro M: X-linked inhibitor of apoptosis (XIAP) and XIAP-associated factor-1 expressions and their relationship to apoptosis in human hepatocellular carcinoma and non-cancerous liver tissues. Oncol Rep 18: 65-70, 2007.

19. Pinho MB, Costas F, Sellos J, Dienstmann R, Andrade PB, Herchenhorn D, Peixoto FA, Santos VO, Small IA, Guimarães DP, et al: XAF1 mRNA expression improves progression-free and overall survival for patients with advanced bladder cancer treated with neoadjuvant chemotherapy. Urol Oncol 27: 382-390, 2009.

20. Huang J, Yao WY, Zhu Q, Tu SP, Yuan F, Wang HF, Zhang YP and Yuan YZ: XAF1 as a prognostic biomarker and therapeutic target in pancreatic cancer. Cancer Sci 101: 559-567, 2010.

21. Chen YB, Shu J, Yang WT, Shi L, Guo XF, Wang FG and Qian YY: XAF1 as a prognostic biomarker and therapeutic target in squamous cell lung cancer. Chin Med J 124: 3238-3243, 2011.

22. Kempkensteffen $C$, Hinz S, Jäger T, Weikert S, Krause H, Schostak M, Christoph F, Strenziok R, Miller K and Schrader M: Expression levels of the IAP antagonists XAF1, Smac/DIABLO and HtrA2 in testicular germ cell tumours. Aktuelle Urol 39: 436-441, 2008 (In German).

23. Ling ZQ, Lv P, Lu XX, Yu JL, Han J, Ying LS, Zhu X, Zhu WY, Fang XH, Wang S, et al: Circulating methylated XAF1 DNA indicates poor prognosis for gastric cancer. PLoS One 8: e67195, 2013.
24. Fang X, Liu Z, Fan Y, Zheng C, Nilson S, Egevad L, Ekman P and Xu D: Switch to full-length of XAF1 mRNA expression in prostate cancer cells by the DNA methylation inhibitor. Int J Cancer 118: 2485-2489, 2006.

25. Zou B, Chim CS, Zeng H, Leung SY, Yang Y, Tu SP, Lin MC, Wang J, He H, Jiang SH, et al: Correlation between the singlesite CpG methylation and expression silencing of the XAF1 gene in human gastric and colon cancers. Gastroenterology 131: $1835-1843,2006$

26. Dai C, Whitesell L, Rogers AB and Lindquist S: Heat shock factor 1 is a powerful multifaceted modifier of carcinogenesis. Cell 130: 1005-1018, 2007.

27. Wang J, He H, Yu L, Xia HH, Lin MC, Gu Q, Li M, Zou B, An X, Jiang $\mathrm{B}$, et al: HSF1 down-regulates XAF1 through transcriptional regulation. J Biol Chem 281: 2451-2459, 2006.

28. Logan IR, McNeill HV, Cook S, Lu X, Meek DW, Fuller-Pace FV, Lunec J and Robson CN: Heat shock factor-1 modulates p53 activity in the transcriptional response to DNA damage. Nucleic Acids Res 37: 2962-2973, 2009.

29. Zhang W, Guo Z, Jiang B, Niu L, Xia G, Wang X, Cheng T, Zhang $\mathrm{Y}$ and Wang $\mathrm{J}$ : Identification of a functional $\mathrm{p} 53$ responsive element within the promoter of XAF1 gene in gastrointestinal cancer cells. Int J Oncol 36: 1031-1037, 2010.

30. Tu SP, Liston P, Cui JT, Lin MC, Jiang XH, Yang Y, Gu Q, Jiang SH, Lum CT, Kung HF, et al: Restoration of XAF1 expression induces apoptosis and inhibits tumor growth in gastric cancer. Int J Cancer 125: 688-697, 2009.

31. Augello C, Caruso L, Maggioni M, Donadon M, Montorsi M, Santambrogio R, Torzilli G, Vaira V, Pellegrini C, Roncalli M, et al: Inhibitors of apoptosis proteins (IAPs) expression and their prognostic significance in hepatocellular carcinoma. BMC Cancer 9: $125,2009$.

32. Kempkensteffen C, Fritzsche FR, Johannsen M, Weikert S, Hinz S, Dietel M, Riener MO, Moch H, Jung K, Krause H, et al: Down-regulation of the pro-apoptotic XIAP associated factor-1 (XAF1) during progression of clear-cell renal cancer. BMC Cancer 9: 276, 2009.

33. Wang Y, Mao H, Hao Q, Wang Y, Yang Y, Shen L, Huang S and Liu P: Association of expression of XIAP-associated factor 1 (XAF1) with clinicopathologic factors, overall survival, microvessel density and cisplatin-resistance in ovarian cancer. Regul Pept 178: 36-42, 2012.

34. Christians ES, Yan LJ and Benjamin I: Heat shock factor 1 and heat shock proteins: Critical partners in protection against acute cell injury. Crit Care Med 30 (Suppl 1): S43-S50, 2002.

35. Westerheide SD and Morimoto RI: Heat shock response modulators as therapeutic tools for diseases of protein conformation. J Biol Chem 280: 33097-33100, 2005.

36. Santagata S, Hu R, Lin NU, Mendillo ML, Collins LC, Hankinson SE, Schnitt SJ, Whitesell L, Tamimi RM, Lindquist S, et al: High levels of nuclear heat-shock factor 1 (HSF1) are associated with poor prognosis in breast cancer. Proc Natl Acad Sci USA 108: 18378-18383, 2011.

37. Li T, Chen CL, Wang JD, Cui SD, Cui DY and Guo W: Expression of heat-shock transcription factor 1 and X-linked inhibitor of apoptosis protein-associated factor-1 in gastrointestinal cancer. Nan Fang Yi Ke Da Xue Xue Bao 28: 487-490, 2008 (In Chinese).

38. Vihervaara A and Sistonen L: HSF1 at a glance. J Cell Sci 127: 261-266, 2014

39. Santagata S, Mendillo ML, Tang YC, Subramanian A, Perley CC, Roche SP, Wong B, Narayan R, Kwon H, Koeva M, et al: Tight coordination of protein translation and HSF1 activation supports the anabolic malignant state. Science 341: 1238303, 2013.

40. Lee MG, Han J, Jeong SI, Her NG, Lee JH, Ha TK, Kang MJ, Ryu BK and Chi SG: XAF1 directs apoptotic switch of p53 signaling through activation of HIPK2 and ZNF313. Proc Natl Acad Sci USA 111: 15532-15537, 2014.

41. Toh CK, Gao F, Lim WT, Leong SS, Fong KW, Yap SP, Hsu AA, Eng P, Koong HN, Thirugnanam A, et al: Never-smokers with lung cancer: Epidemiologic evidence of a distinct disease entity. J Clin Oncol 24: 2245-2251, 2006.

42. Govindan R, Ding L, Griffith M, Subramanian J, Dees ND, Kanchi KL, Maher CA, Fulton R, Fulton L, Wallis J, et al: Genomic landscape of non-small cell lung cancer in smokers and never-smokers. Cell 150: 1121-1134, 2012 .

43. Gou LY, Niu FY, Wu YL and Zhong WZ: Differences in driver genes between smoking-related and non-smoking-related lung cancer in the Chinese population. Cancer 121 (Suppl 17): S3069-S3079, 2015. 